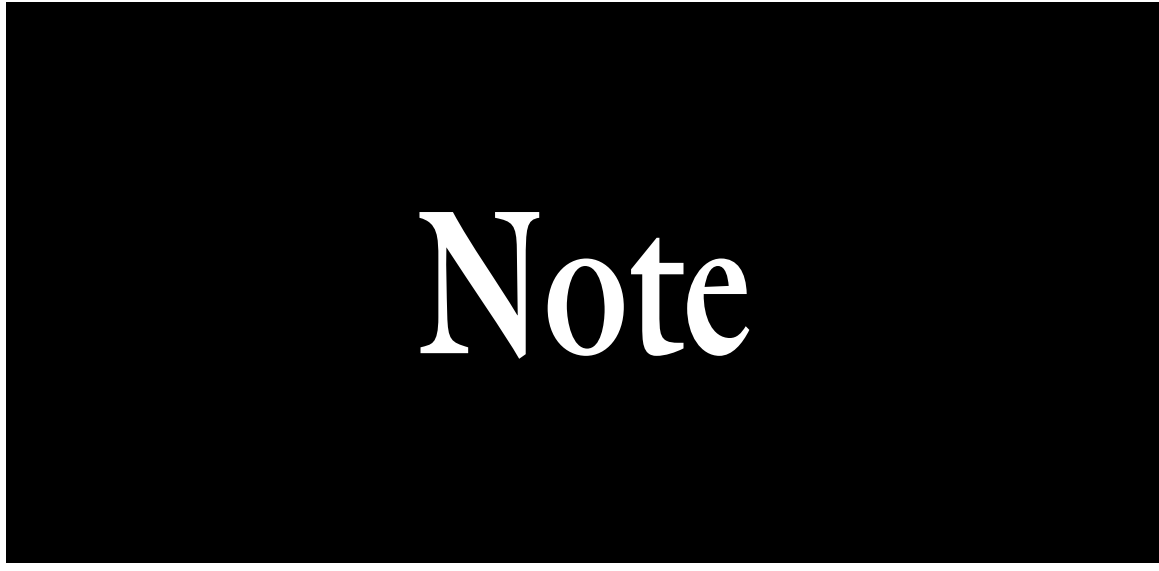

\section{Using a Spreadsheet to Model Rain Barrel Efficiency and Cost Benefit for Homeowners}

\author{
Joanne Logan ${ }^{1}$
}

ADDITIONAL INDEX WORDs. irrigation management, vegetable garden

SUMMARY. By collecting rain from a roof during rain events and storing it in a barrel or cistern, homeowners can create an alternative water supply to irrigate their home gardens and landscaping that will not overpump the groundwater or increase the water bill. In this example, a typical home garden would be $400 \mathrm{ft}^{2}$ on which the homeowner plans to irrigate using a 55-gal heavy-duty plastic barrel with a spigot located near the bottom of the tank. The objective of this study was to develop a spreadsheet-based model using daily data to determine how the watering habits of home gardeners affect the amount of available supplemental irrigation water and cost savings using a typical 55-gal rain barrel, thus resulting in a more realistic costbenefit analysis. The model allows for multiple, user-selected criteria such as the size of the barrel, number of barrels, harvest efficiency of the guttering system, size of the garden, the catchment area, and the watering habits of the homeowner (such as how many days without precipitation have occurred before they feel the need to water), which were used to develop seven different scenarios. To optimize rainwater use and cost benefits, the following parameters are recommended: catchment area of $600 \mathrm{ft}^{2}, 90 \%$ harvest efficiency by reducing leaks and other problems with guttering and rain barrel, threshold of 0.10 inch for a wet day, minimum of only 2 dry days before using the water in the barrel, and one overflow barrel. In this case,

a homeowner in Knoxville, TN, can harvest an average of 1570 gal per season (range of 1076-2076 gal), at an average cost savings of \$22, and thus recover the cost of the two barrels in 3-6 years.

A home food garden is an excellent resource to reduce household expenses and improve the health and nutrition of the family. There has been a recent increase in food gardening in the United States and in $2008,31 \%$ of U.S. households had a food garden. In 2009, the median size of food gardens in the United States was $96 \mathrm{ft}^{2}$, the average size was $600 \mathrm{ft}^{2}$, and $75 \%$ of home gardens were at least $400 \mathrm{ft}^{2}$ (National Gardening Association, 2009). Vegetables are

Department of Biosystems Engineering and Soil Science, University of Tennessee, 2506 EJ Chapman Drive, Knoxville, TN 37996-4531

${ }^{1}$ Corresponding author. E-mail: loganj@utk.edu.
$80 \%-95 \%$ water and therefore their yield and quality suffer very quickly from drought (Sanders, 1993; Straw, 2009). In many regions of the United States, supplemental irrigation is recommended to optimize vegetable crop yield. In the United States, outdoor water use, including food gardens, is about $30 \%$ on average of total residential potable water use (Vickers, 2001).

Rainwater harvesting is an ancient technique enjoying a revival in popularity because of the inherent quality of rainwater and the interest in reducing consumption of potable water (Krishna, 2005). Parts of Australia and the southwestern United States have embraced rainwater harvesting as a serious way to augment sparse and irregular water supplies (Lancaster, 2010). In Chicago, during the period 2004-07, 3000 rain barrels were distributed for free to homeowners (Ando and Freitas, 2011).

A catchment area for the collection of rainwater can be any area that collects or sheds rainwater. A roof is the most common and easily accessible area to use for rainwater collection; it uses gravity to direct the water. Most homes are equipped with a guttering system that can easily be adapted to funnel water to a storage tank. For general calculations, $\approx 0.5$ gal of water per square foot of roof area can be collected and stored during a $\mathrm{l}$-inch rainfall. Some rainfall evaporates from the roof or leaks from the gutters, so an overall efficiency of $80 \%$ to $85 \%$ is often used in the calculation of harvested water. A rainfall event of $\approx 0.5$ inch will easily fill a 50 to 55 -gal barrel; planter beds, vegetable or flower gardens, and potted plants can easily be irrigated with the water from a rain barrel (Watson, 2010). Water is either pumped or allowed to flow by gravity to a nearby garden or landscaped area (P. Gibson, personal communication).

Many reports about the potential of rainwater harvesting use annual or seasonal rainfall and take into account only the size of the catchment area and efficiency of the guttering system (harvest efficiency). However, there are many other factors that should be considered to better estimate the amount of harvested water and associated cost savings. These factors

\begin{tabular}{llll}
\hline $\begin{array}{l}\text { Units } \\
\begin{array}{l}\text { To convert U.S. to SI, } \\
\text { multiply by }\end{array}\end{array}$ & U.S. unit & SI unit & $\begin{array}{l}\text { To convert SI to U.S., } \\
\text { multiply by }\end{array}$ \\
\hline 0.0929 & $\mathrm{ft}^{2}$ & $\mathrm{~m}^{2}$ & 10.7639 \\
0.0283 & $\mathrm{ft}^{3}$ & $\mathrm{~m}^{3}$ & 35.3147 \\
3.7854 & gal & $\mathrm{L}$ & 0.2642 \\
40.7458 & gal $/ \mathrm{ft}^{2}$ & $\mathrm{~L} \cdot \mathrm{m}^{-2}$ & 0.0245 \\
25.4 & inch $(\mathrm{es})$ & $\mathrm{mm}$ & 0.0394
\end{tabular}


include the size of the garden, length of a dry spell that would trigger use of rainwater from the barrel, and how much water is in the barrel before the homeowner decides to use it. Most of these factors involve day-to-day decisions by the homeowner, and support the use of a model based on daily data. Taking these factors into consideration will help the extension agent or other consultant to provide a more realistic cost-benefit analysis of a typical rain barrel.

The objective of this study was to develop a spreadsheet-based model based on daily weather data in Excel ${ }^{\circledR}$ (Microsoft Corp., Redmond, WA) to determine how the watering habits of home gardeners affect the amount of available supplemental irrigation water and cost savings using a typical 55-gal rain barrel.

\section{Materials and methods}

Daily rainfall from 1981 to 2012 (1 May to 15 Oct.) for Knoxville, TN, was obtained from the Southern Region Climate Center (2013). Rain amounts of 0.05 inch or less were not used (assumed that such a small amount of rainfall would evaporate from the roof). An Excel $^{\circledR}$ spreadsheet created to calculate daily rainwater harvested from a single rain barrel was designed to be flexible and allow the input of five criteria related to the rainwater harvesting system and the homeowner practices or preferences: size of catchment area, number of barrels, efficiency of harvesting (related to condition of guttering and downspouts), threshold and number of dry days before the barrel water was used, and threshold of daily rainfall that prohibits use of barrel water because it is too wet. Cost analysis for Knoxville was based on the 2012 rate of $\$ 10.75$ per $100 \mathrm{ft}^{3}$ for water and wastewater. The daily model was calculated for each year from 1981 to 2012 for seven scenarios and the final recommendation; reported data are mean, maximum, and minimum.

SCENARIOs. Although numerous combinations of "rain barrel habits" affecting the potential for rainwater harvesting are possible, seven scenarios are presented as examples.

The first scenario (Table 1 ) assumed a $600-\mathrm{ft}^{2}$ catchment area, $80 \%$ harvest efficiency, and $100 \%$ use of all the collected rainwater in a single rain barrel (no siphoning to additional barrels). This scenario sets the upper threshold for rain water harvesting, although it is unlikely that a homeowner would be able or willing to use the full amount for irrigating a home garden. The average (1981-2012) seasonal rainfall in Knoxville was 21.11 inches, and ranged from 13.01 to 33.74 inches over the 32 -year period. Removing all rainfall events of 0.05 inch or less and applying an $80 \%$ harvest efficiency resulted in average seasonal effective rainfall of 16.55 inches, with a range from 10.22 to 26.67 inches. Rainwater harvesting from a typical $600-\mathrm{ft}^{2}$ catchment area provided an average of 6188 gal (112.5 55-gal barrels), with a range from 3821 gal (69.5 barrels) to 9975 gal (181.4 barrels) over the 32-year period. At current costs of potable water (including a wastewater fee) in Knoxville, this scenario resulted in an annual savings of $\$ 89$, with a range from $\$ 55$ to $\$ 143$. This scenario suggested that the average cost of a rain barrel $(\$ 50)$ could be recovered in a single year.

The second scenario (Table 1) was similar to the first, except it was assumed that the barrel was not emptied when full, so that the maximum collected amount was $\mathbf{5 5}$ gal for any given day. In this scenario, rainwater harvesting provided an average of $1912 \mathrm{gal}$ (34.8 barrels), with a range from $1154 \mathrm{gal}$ (21.0 barrels) to 2839 gal (51.6 barrels). This scenario resulted in an annual savings of $\$ 27$, with a range from $\$ 17$ to $\$ 41$, implying that the cost of a rain barrel could be recovered over 2-3 years.

A third, and more realistic, scenario (Table 1 ) assumed that the homeowner did not use the rain barrel if it rained more than 0.25 inch on a given day or if the level in the barrel was less than $25 \mathrm{gal}$, and only used the collected rainwater if the sequence of dry (user defined as rainfall $\leq 0.05$ inch) days was $3 \mathrm{~d}$ or more. In this scenario, rainwater harvesting provided an

Table 1. Estimated seasonal irrigation supply of a 55-gal rain barrel for seven scenarios and final recommendation for homeowner "habits" in Knoxville, TN.

\begin{tabular}{|c|c|c|c|c|c|c|}
\hline $\begin{array}{l}\text { Scenario } \\
\text { no. }^{\mathrm{z}}\end{array}$ & $\begin{array}{l}\text { Catchment } \\
\text { area }\left(\mathrm{ft}^{2}\right)^{\mathrm{y}}\end{array}$ & $\begin{array}{c}\text { Barrels } \\
\text { (no.) }\end{array}$ & $\begin{array}{c}\text { Harvest } \\
\text { efficiency (\%) }\end{array}$ & Homeowner "habits"x & $\begin{array}{l}\text { Harvested water [mean, } \\
\max , \min (\mathrm{gal})]^{\mathrm{w}}\end{array}$ & $\begin{array}{l}\text { Savings [mean, } \\
\max , \min (\$)]\end{array}$ \\
\hline 1 & 600 & 1 & 80 & Use all collected water & $6188,9975,3821$ & $89,143,55$ \\
\hline 2 & 600 & 1 & 80 & Maximum of 55 gal per day & $1912,2839,1154$ & $27,41,17$ \\
\hline 3 & 600 & 1 & 80 & Only used when 25 gal in barrel, & $698,870,440$ & $10,12,6$ \\
\hline 4 & 300 & 1 & 80 & no rain $>0.25$ inch that day, & $626,801,409$ & $9,12,6$ \\
\hline 5 & 1200 & 1 & 80 & dry previous $3 \mathrm{~d}$ & $724,915,488$ & $10,13,7$ \\
\hline 6 & 600 & 2 & 80 & & $1285,1544,819$ & $18,22,12$ \\
\hline 7 & 600 & 2 & 80 & $\begin{array}{l}\text { Only used when } 25 \text { gal in barrel, } \\
\text { no rain }>0.25 \text { inch that day, } \\
\text { dry previous } 5 \mathrm{~d}\end{array}$ & $420,605,205$ & $6,9,3$ \\
\hline Recommended & 600 & 2 & 90 & $\begin{array}{l}\text { Only used when } 25 \text { gal in barrel, } \\
\text { no recent rain }>0.10 \text { inch that } \\
\text { day, dry previous } 2 \mathrm{~d}\end{array}$ & $1570,2076,1076$ & $22,30,15$ \\
\hline
\end{tabular}

\footnotetext{
${ }^{\mathrm{z}}$ Scenario $\mathrm{l}=600-\mathrm{ft}^{2}$ catchment area, $80 \%$ harvest efficiency, $100 \%$ use of the all collected rainwater in a single rain barrel (no siphoning to additional barrels); Scenario $2=$ similar to Scenario 1, except it was assumed that the barrel was not emptied when full, so that the maximum collected amount was 55 -gal for any given day; Scenario $3=$ assumes that the homeowner did not use the rain barrel if it rained more than 0.25 inch on a given day or if the level in the barrel was less than 25 gal, and only used the collected rainwater if the sequence of dry (user defined as rainfall $\leq 0.05 \mathrm{inch}$ ) days wsed from 600 toas $3 \mathrm{~d}$ or more; Scenario $4=$ same as Scenario 3 except catchment area reduced from 600 to $300 \mathrm{ft}^{2} ;$ Scenario $5=$ same as Scenario 3 except catchment area increa $1200 \mathrm{ft}^{2}$; Scenario $6=$ same as Scenario 3 except includes a second barrel of equal capacity $(55$-gal $)$ to capture the overflow water from the first barrel; Scenario $7=$ same as Scenario 3 except increases the number of dry days from $3 \mathrm{~d}$ to $5 \mathrm{~d}$ before using the water.

${ }^{\mathrm{y}} 1 \mathrm{ft}^{2}=0.0929 \mathrm{~m}^{2}$.

${ }^{\mathrm{x}} 1 \mathrm{gal}=3.7854 \mathrm{~L}, 1 \mathrm{inch}=25.4 \mathrm{~mm}$.

${ }^{\mathrm{w}} \max =$ maximum; $\min =$ minimum.
} 
average of $698 \mathrm{gal}$ (12.7 barrels), with a range from $440 \mathrm{gal}$ ( 8.0 barrels $)$ to 870 gal ( 15.8 barrels). This scenario resulted in an annual savings of $\$ 18$, with a range from $\$ 12$ to $\$ 22$, suggesting that the cost of a rain barrel would take $4-8$ years to recover the cost of the rain barrel.

Using the same factors as in the third scenario to investigate the effect of catchment area, a fourth scenario (Table 1) showed that a decrease in the catchment area from $600 \mathrm{ft}^{2}$ to $300 \mathrm{ft}^{2}$ (the size of a garage or shed) provided only $626 \mathrm{gal}$ (11.4 barrels), with a range from 409 gal $(7.4$ barrels) to $801 \mathrm{gal}$ (14.6 barrels). However, scenario 5 (Table 1 ) with a doubling of the catchment area to $1200 \mathrm{ft}^{2}$ (about half of an average roof in the United States) had very little beneficial effect due to the small capacity of the 55-gal barrel.

In the sixth scenario (Table 1), the model showed that using a second barrel of equal capacity ( $55 \mathrm{gal}$ ) to capture the overflowing water from the first barrel increased the average seasonal harvested water to $1285 \mathrm{gal}$ (23.4 barrels), with a range from 819 gal (14.9 barrels) to 1544 gal (26.1 barrels).

To investigate the effect of user preference of number of days without precipitation before using the water in the rain barrel, a seventh scenario (Table 1) showed that increasing the number of dry days from $3 \mathrm{~d}$ to $5 \mathrm{~d}$ before using the water in the barrel reduced the amount to $420 \mathrm{gal}$ (7.6 barrels), with a range from $205 \mathrm{gal}$ (3.7 barrels) to $605 \mathrm{gal}$ (11.0 barrels), so this is not a recommended practice and homeowners should empty the barrel as frequently as possible. Changing the amount in the barrel required before emptying had little effect on the outcome.

Based on the results of the model for Knoxville, TN, the following parameters are recommended (Table 1 ): catchment area of $600 \mathrm{ft}^{2}, 90 \%$ harvest efficiency by reducing leaks and other problems with guttering and rain barrel, threshold of 0.10 -inch precipitation for a wet day, minimum of only $2 \mathrm{~d}$ without precipitation before using water in the barrel, and using one overflow barrel. In this case, the homeowner in Knoxville, TN, annually can harvest an average of 1570 gal (28.5 barrels), at a cost savings of $\$ 22$, and thus recover the cost of the two barrels in 3-6 years. Because a 400$\mathrm{ft}^{2}$ food garden in Knoxville, TN requires an additional 2388 gal (43.4 barrels) of supplemental water (average of 32 years), successful rain water harvesting would meet about $66 \%$ of the seasonal irrigation water demands.

\section{Literature cited}

Ando, A.W. and L.P.C. Freitas. 2011. Consumer demand for green stormwater management technology in an urban set- ting: The case of Chicago rain barrels. Water Resources Res. 47:W12501.

Krishna, H.J. 2005. The Texas manual on rainwater harvesting. 7 June 2013. <http:// www.ecy.wa.gov/programs/wr/hq/pdf/ texas_rw_harvestmanual_3rdedition.pdf $>$.

Lancaster, B. 2010. Rainwater harvesting for drylands and beyond. 5 Sept. 2013. <http://www.harvestingrainwater.com/ rainwater-harvesting-inforesources $/>$.

National Gardening Association. 2009. The impact of home and community gardening in America. 23 May 2013. $<$ http://www.gardenresearch.com/ files / 2009-Impact-of-Gardening-inAmerica-White-Paper.pdf $>$.

Sanders, D.C. 1993. Vegetable crop irrigation. 9 Sept. 2013. <http://www.ces. ncsu.edu/hil/hil-33-e.html>.

Southern Region Climate Center. 2013. Climate information for management and operational decisions (CLIMOD). 7 June 2012. <http://climod.srcc.lsu.edu>.

Straw, R.A. 2009. Irrigating the home garden. 29 Sept. 2013. <http://pubs. ext.vt.edu/426/426-322/426-322.html .

Vickers, A. 2001. Handbook of water use and conservation. WaterPlow Press, Amherst, MA.

Watson, G. 2010. Rain barrels: A homeowner's guide. 7 June 2013. <http:// www.swfwmd.state.fl.us/publications / files/rain_barrels_guide.pdf $>$. 